\title{
A Motion Control of a Robotic Walker for Continuous Assistance during Standing, Walking and Seating Operation
}

\author{
Daisuke Chugo ${ }^{1}$ and Kunikatsu Takase ${ }^{2}$ \\ ${ }^{1}$ Kwansei Gakuin University, Hyogo, \\ ${ }^{2}$ The University of Electro-Communications, Tokyo, \\ Japan
}

\section{Introduction}

In Japan, the population ratio of senior citizen who is 65 years old or more exceeds 22[\%] at February 2009 and rapid aging in Japanese society will advance in the future (Population Estimates, 2009). In aging society, many elderly people cannot perform normal daily household, work related and recreational activities because of decrease in force generating capacity of their body. Today, the 23.5[\%] of elderly person who does not stay at the hospital cannot perform daily life without nursing by other people (Annual Reports, 2001). For their independent life, they need a domestic assistance system which enable them to perform daily activities alone easily even if their physical strength reduces.

Usually, their daily activities consist of standing, walking and seating operation continuously. Especially, standing up motion is the most serious and important operation in daily life for elderly person who doesn't have enough physical strength (Alexander et al., 1991) (Hughes \& Schenkman, 1996). In typical bad case, elderly person who doesn't have enough physical strength will cannot operate standing up motion and will falls into the wheelchair life or bedridden life. Furthermore, if once elderly person falls into such life, the decrease of physical strength will be promoted because he will not use his own physical strength (Hirvensalo et al., 2000).

In previous works, many researchers developed assistance devices for standing up motion (Nagai et al., 2003) (Funakubo et al., 2001). However, these devices are large scale and they are specialized in only "standing assistance". Therefore, the patient has to use other assistance device for their daily activities, for example when they want to walk after standing operation, and these devices are not suitable for family use. Furthermore, these devices assist all necessary power for standing up and they do not discuss the using the remaining physical strength of patients. Thus, there is a risk of promoting the decrease of their physical strength. On the other hand, devices based on the walking assistance system which can assist the standing and walking operation are developed (Chuv et al., 2006) ( Pasqui \& Bidaud, 2006). However in these devices, the patient has to maintain his body posture using his physical strength and it is difficult operation for elderly.

Therefore, we are developing a rehabilitation walker system with standing assistance device which uses a part of the remaining strength of the patient in order not to reduce their 
muscular strength. Our system is based on a walker which is popular assistance device for aged person in normal daily life and realizes the standing motion using the support pad which is actuated by novel manipulator with three degrees of freedom.

From opinions of nursing specialists, required functions for daily assistance are (1) the standing assistance which uses a remaining physical strength of the patient maximally, (2) the posture assistance for safety and stability condition during standing, walking and seating assistance continuously, (3) the position adjustment assistance especially before seating and (4) the seating assistance to a target chair. In our previous work, we developed a force assistance scheme which realizes function (1) (Chugo et al., 2007). Therefore, in next step, for realizing function (2) and (3), we develop an active walker system in this paper. Please note function (4) will be our future work.

In this paper, our key ideas are the following two topics. First topic is a novel stability control scheme during standing up motion using the active walker function. Our active walker coordinates the assisting position cooperating the standing assistance manipulator according to the posture of the patient. Second topic is a seating position adjustment scheme using interactive assistance. Usually, an adjustment operation of the accurate position is difficult for elderly people and this operation has high risk of falling down (Hatayama \& Kumagai, 2004). Therefore, this function is most important for walking assistance systems.

This paper is organized as follows: we introduce the mechanical design and controller of our system in section 2; we propose the body stability control scheme in section 3; we propose the seating position adjustment scheme in section 4 ; we show the result of experiments using our prototype in section 5 ; section 6 is conclusion of this paper.

\section{System configuration}

\subsection{Assistance mechanism}

Fig.1 shows overview of our proposed assistance system. Our system consists of a support pad with three degrees of freedom and an active walker system. The support pad is actuated by proposed assistance manipulator mechanism with four parallel linkages. The patient leans on this pad during standing assistance. Our active walker is actuated by two brushless motors on each front wheel. (We discuss in next paragraph.) Fig.2 shows our prototype. Our prototype can lift up the patient of $1.8[\mathrm{~m}]$ height and $150[\mathrm{~kg}]$ weight maximum, and it can assist him during walking using actuated wheels.

Fig. 3 shows our developed support pad based on the opinions of nursing specialists at a welfare event (Chugo \& Takase, 2007). The support pad consists of the pad with low repulsion cushion and arm holders with handles. In general, a fear of falling forward during standing motion reduces the standing ability of elderly person (Maki et al., 1991). Using this pad, a patient can maintain his posture easily during standing up motion without a fear of falling forward. Furthermore, the pad has two force sensors in its body (We discuss in section 3.). Our assistance system can measure its applied force and can estimate a body balance of the patient during standing up motion using these sensors.

\subsection{Controller}

Our developed control system is shown in Fig.4. Our assistance walker consists of two parts, a standing assistance system and an active walker system. The standing assistance system has three DC motors and three potentiometers in each joint and two force sensors on the arm holder. Motors are connected each joint using worm gears, thus, our manipulator can maintain its posture even if system power is down. 


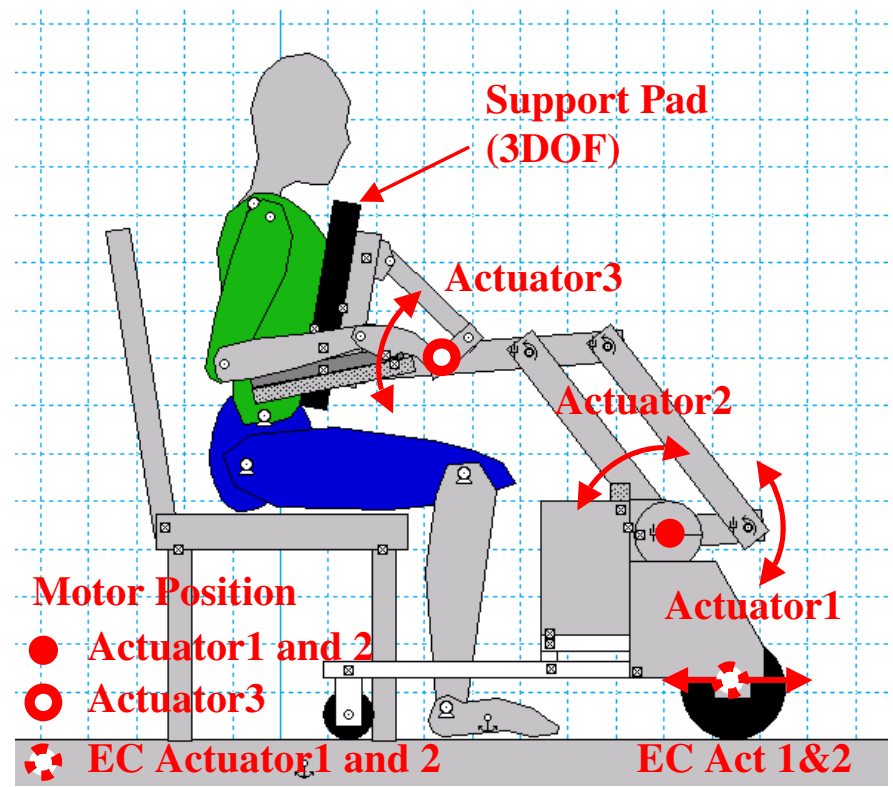

Fig. 1. Overview of our system.

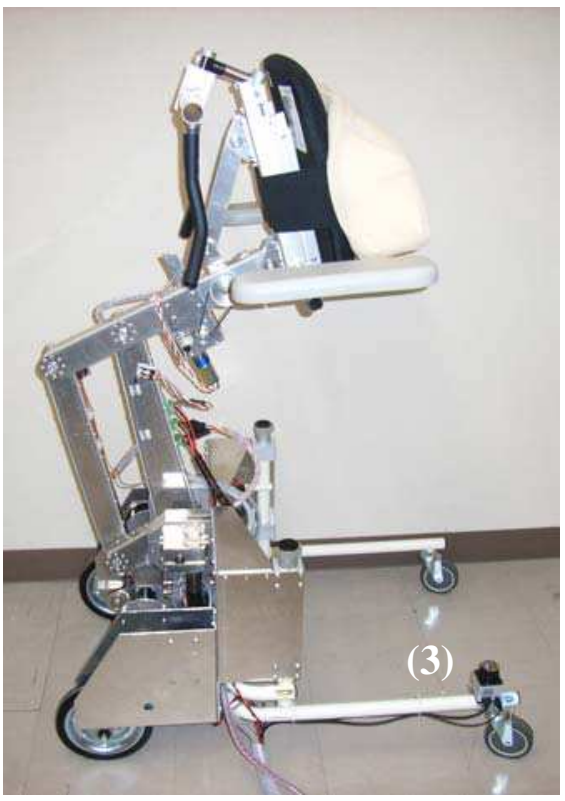

(a) Side View

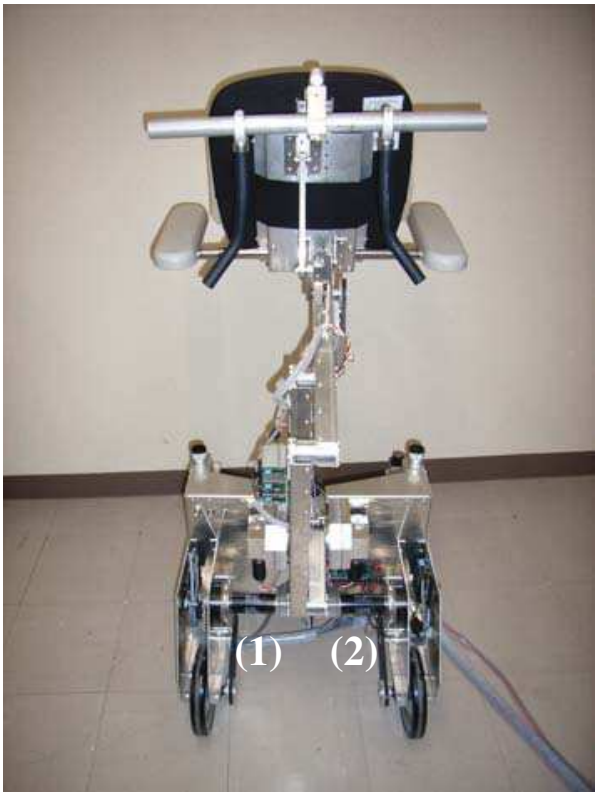

(b) Front View

Fig. 2. Our prototype. Its weight is about $35[\mathrm{~kg}]$ without batteries. Our prototype requires an external power supply and control PC. (In future works, we will use batteries and built-in controller.) (1) is EC Actuator 1 and (2) is EC Actuator 2. (3) is LRF. 


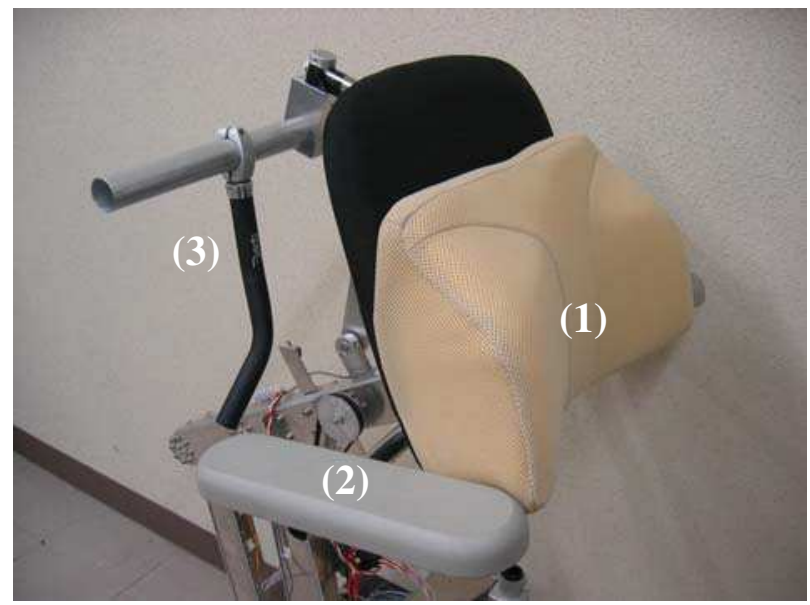

(a) Support Pad

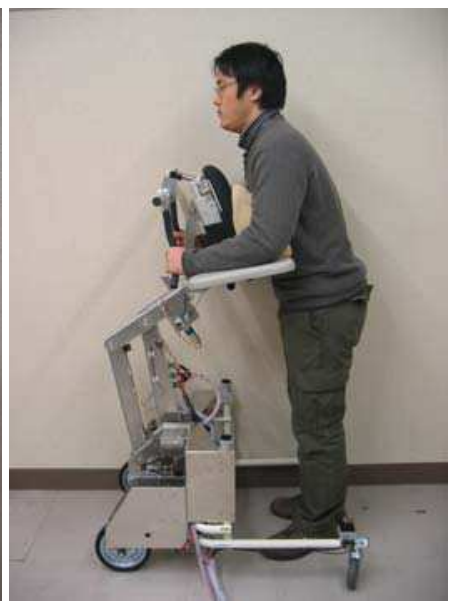

(b) Assistance Posture

Fig. 3. Our proposed support pad. (1) is the pad with a low repulsion cushion, (2) is the arm holder and (3) is a handle. Its diameter is $0.24[\mathrm{~m}]$ which is easy to grip for the elderly.

The active walker system has two Maxson brushless EC motors and two electromagnetic brakes in each front wheel. ((1) and (2) in Fig.2 (b)) Electromagnetic brakes can stop the walker when the patient seems to fall down. This break can hold the walker when it assists the $150[\mathrm{~kg}]$ weight patient maximum. These EC motors can operate with traction force limitation and can follow when the patient push the walker against to the advance direction. These advantageous characteristics are useful for the active walker considering with safety reason.

Our system has two laser range finders which can measure objects within $4[\mathrm{~m}]$ and wireless LAN adapter. The system can receive its position data at real time from the indoor positioning system which is equipped in the patient's room. (We discuss in section 4 closely.)

\subsection{Problem specification}

We questions to nursing specialists about required assistance for aged people in their daily life. Their results are the followings.

- Aged person requires standing, walking and seating assistance continuously by a same device. In typical required case, he stands up from the bed, he walks to the toilet and he sits on it by himself using the assistance system.

- When he stands up, he requires power assistance for reducing the load and he also requires position assistance for maintaining his body balance.

- When he sits on the target seat, he requires the position adjustment assistance. A failure of this motion causes a serious injury, therefore, this assistance is important.

In our previous works, a reducing the load during standing is realized (Chugo \& Takase, 2007). Therefore, in this paper, we focus on (1) the assistance for stable posture during standing to walking motion and (2) the position adjustment assistance to target seating position. 


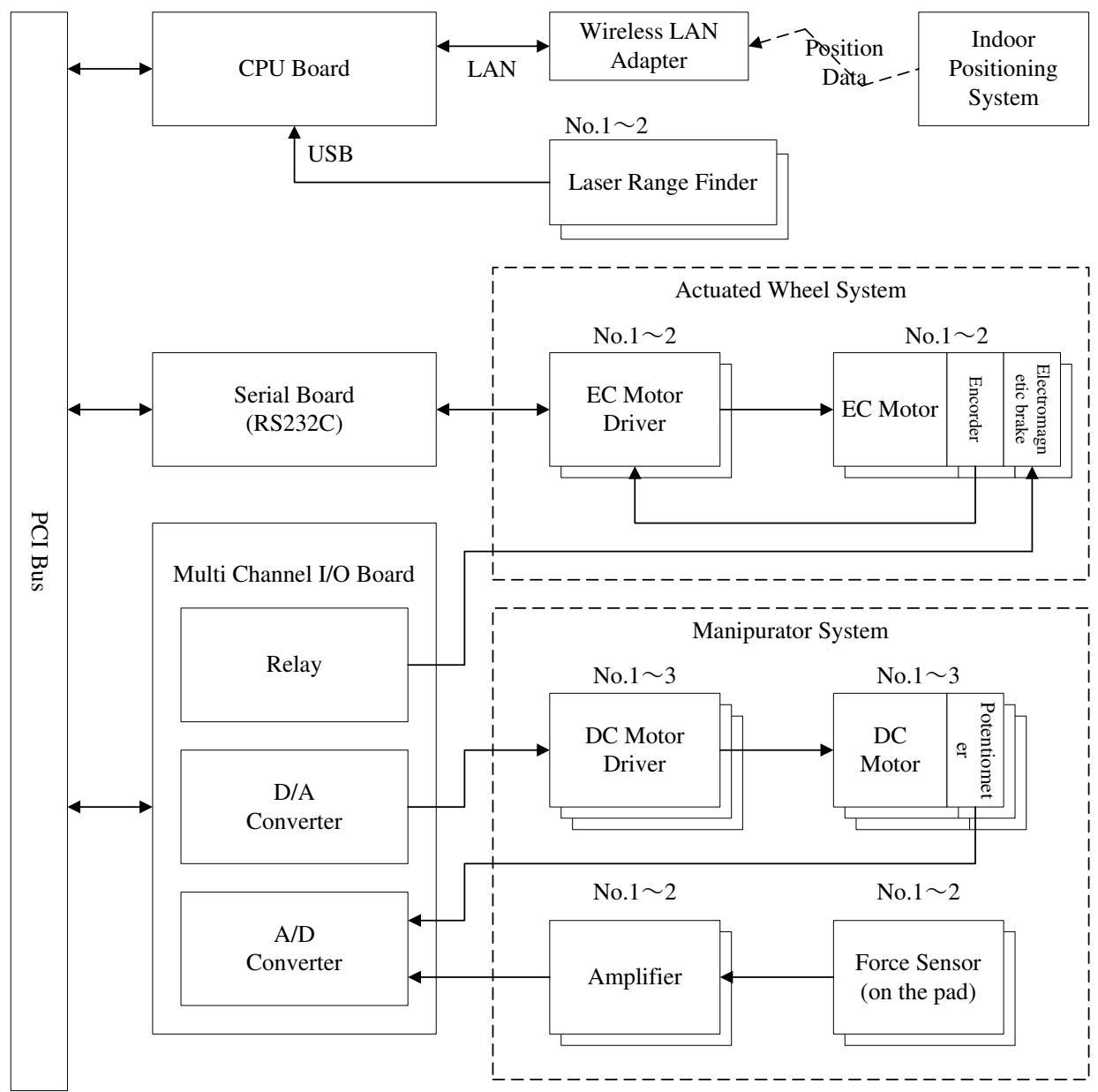

Fig. 4. Overview of our control system.

\section{Body stability control}

\subsection{Motion by nursing specialists}

In previous study, many standing up motions for assistance are proposed. Kamiya (Kamiya, 2005) proposed the standing up motion which uses remaining physical strength of the patients based on her experience as nursing specialist. Fig.5(a) shows the standing up motion which Kamiya proposes.

In our previous work, we analyze this standing up motion and find that Kamiya scheme is effective to enable standing up motion with smaller load (Chugo et al., 2006). We assume the standing up motion is symmetrical and we discuss the motion as movement of the linkages model on 2D plane (Nuzik et al., 1986). We measure the angular values among the linkages, which reflect the relationship of body segments. The angular value is derived using the body landmark as shown in Fig.5(b). 


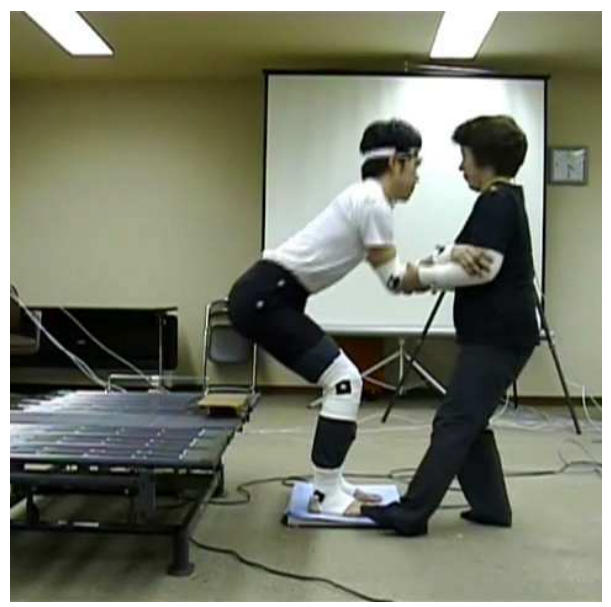

(a) Assistance Motion

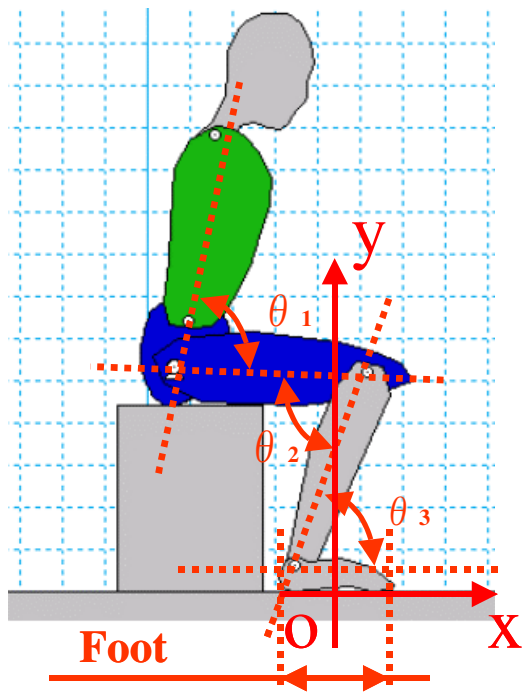

(b) Coordination

Fig. 5. Standing-up motion with Kamiya scheme. $\theta_{1}$ shows the angular of the pelvis and the trunk. $\theta_{2}$ and $\theta_{3}$ show the angular of the knee and the ankle, respectively.

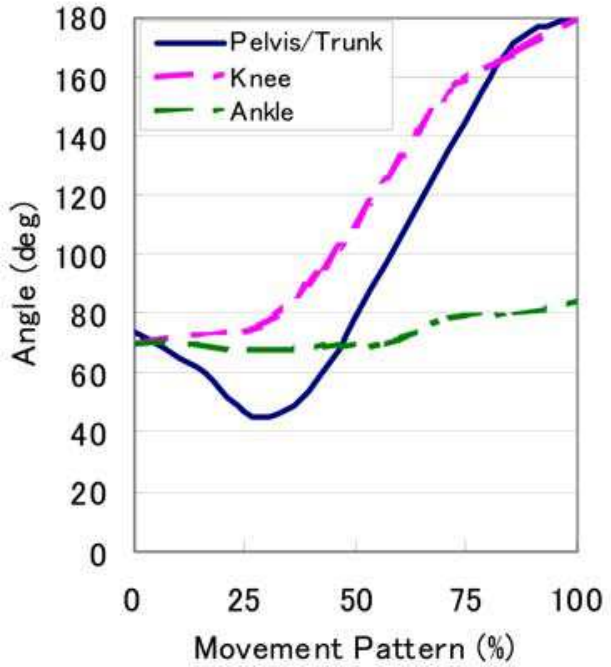

(a) Angular value

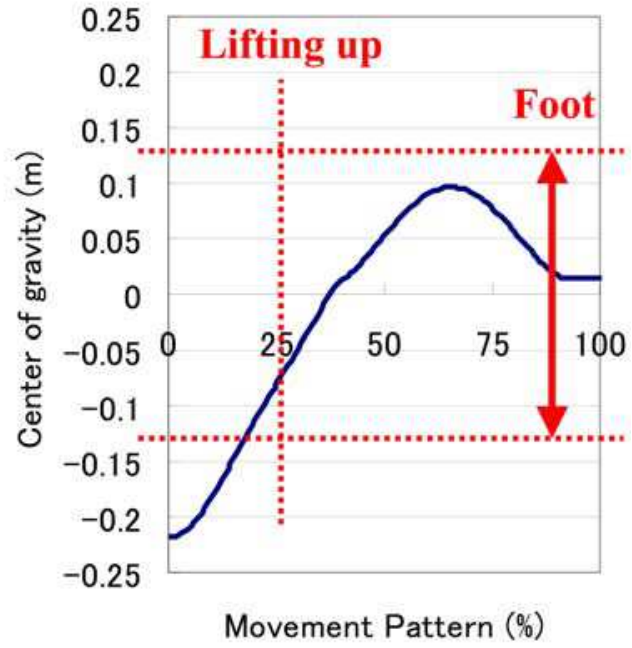

(b) Position of COG

Fig. 6. Analysis result of standing-up motion with Kamiya scheme. Foot size of human model is $0.26[\mathrm{~m}]$ and his foot area is shown by red arrow in (b). Before 25[\%] movement pattern, he still sits on a chair.

In order to realize the Kamiya scheme, the trunk needs to incline to forward direction during lifting up from chair as shown in Fig.6(a). Y-axis shows the angular value (Pelvis and 
trunk, knee, ankle) and X-axis shows the movement pattern (Hughes \& Schenkman, 1996) which means the ratio of standing up operation as (1). Fig.6(b) shows the position of the patient's center of gravity (COG) which indicates the body balance of the patient during standing up motion.

$$
\hat{s}=\frac{t}{t_{s}}
$$

where $t_{s}$ is required time to the standing up operation and $t$ is present time.

Generally, inclining the trunk reduces the load of knee during standing up (Schenkman et al., 1990). Furthermore, the position of the patient's center of gravity (COG) is in areas of his foot $( \pm 0.13[\mathrm{~m}])$ during standing up operation. This means his body balance is maintained. Therefore, this motion is useful for elderly person who doesn't have enough physical strength.

\subsection{Required condition}

In standing up motion of Kamiya scheme, we can divide the standing up motion into four phases (Nuzik et al., 1986). In first phase, the patient inclines his trunk to forward direction. In second phase, he lifts off from the chair and in third phase (as shown in Fig.5(a)), he lifts the body. In fourth phase, he extends his knee joint completely and ends the standing up motion.

In previous study, for realizing the motion of Kamiya scheme (Kamiya, 2005), the conditions are discussed as follows.

- In third phase, it is required to reduce the knee load.

- In other phases, it is required to maintain the standing up motion with stably posture.

Thus, in our previous work, the assistance manipulator uses a damping control in third phase and in other phases, it uses a position control (Chugo et al., 2007). Using this scheme, the patient's load reduces in third phase and in other phases, the patient is required to use own physical strength. The reference of position control is based on the standing up motion of nursing specialist as Fig.6(a) and the body posture of the patient is maintained during standing up operation. However, in third phase, our assistance system uses a damping control and it cannot guarantee his body balance.

Therefore, it is required to maintain his body balance during standing up motion using the active walker function.

\subsection{Force control of active walker}

For realizing the required condition, we maintain the COG of the patient as an index of body balance. We use PID controller as (2) and coordinate the COG. The coordination of our system is shown in Fig.7.

$$
\begin{gathered}
\tau=k_{p} e+k_{i} \int e d t+k_{d} \frac{d e}{d t} \\
e=x_{C O G}-x_{C O G}^{r e f} \\
\mathbf{x}_{C O G}^{r e f}=\left[x_{C O G}^{r e f}(0), \cdots, x_{C O G}^{r e f}(\hat{s}), \cdots, x_{C O G}^{r e f}(1)\right]^{T}
\end{gathered}
$$




$$
\tau_{\text {out }}=\left\{\begin{array}{cc}
\tau & \left(|\tau|<\tau_{0}\right) \\
\tau_{0} & \left(|\tau| \geq \tau_{0}\right)
\end{array}\right.
$$

where $\tau$ is force reference of the active walker and $x_{\mathrm{COG}}$ is the actual position of COG. $x_{\mathrm{COG}}^{\text {ref }}$ is the position reference of COG (Fig.6(b)) and it is function of the movement pattern $\hat{s}$ as (4). $k_{p}, k_{i}, k_{d}$ are proportional, integral and derivative gain of PID controller, respectively. $\tau_{\text {out }}$ is actual output force of the active walker as (5). For safety reason, output force is limited to $\tau_{0}$.

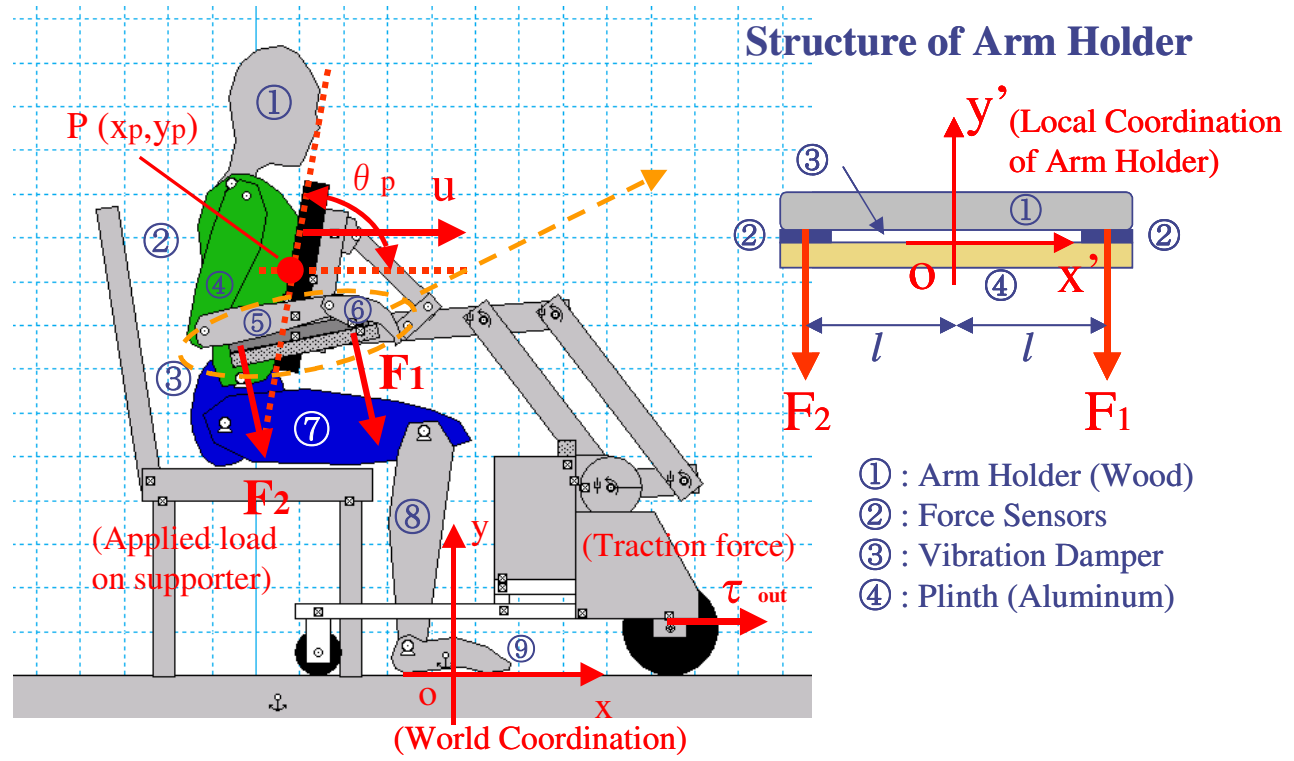

Fig. 7. Coordination and structure of the arm holder.

\subsection{Posture estimation}

Our proposed force control of the active walker requires the information of the position of COG. Usually, COG is measured using a force plate, however, this device is not suitable in practical use. Thus, it is required to estimate the position of COG with the sensors equipped on this walker. Our proposed walker has two force sensors on its arm holder as Fig.7. $F_{1}$ is the applied force of the front part of the arm holder and $F_{2}$ is one of its back part. When the COG moves to ahead, $F_{1}$ is heavier than $F_{2}$ and when it moves to back, $F_{2}$ is heavier than $F_{1}$. Therefore, using $F_{1}$ and $F_{2}$, we can estimate the COG.

We discuss the relationship between the COG and applied force to the pad in preliminary experiment using five subjects. Fig.8(a) shows the relationship between the position of COG (which is measured by a force plate) and COG on force sensors as (6) when the angle of support pad is $70[\mathrm{deg}]$.

$$
x_{\mathrm{COG}}^{f}=\frac{\left(F_{1}-F_{2}\right) \cdot l}{F_{1}+F_{2}}
$$


where $l$ is distance between two sensors as Fig.7.

Subjects are adult male with the special wearing equipment for the experience of the elderly (Takeda et al., 2001). From these results, both values seem to be proportional as Fig.8(a). In Fig.8(a), we show an approximation line of Subjects A.

Furthermore, Fig.8(b) shows the relationship between the COG on force sensors and the angle of the support pad when the COG of patient is zero. From these results, COG on force sensors moves according to the angle of support pad.

From this experiment, we can estimate the COG comparing with the measuring values of force sensors and these data which are derived in this preliminary experiment.

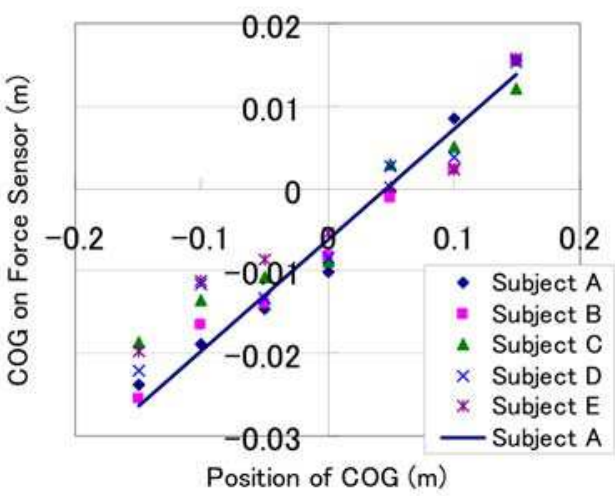

(a) The position of COG

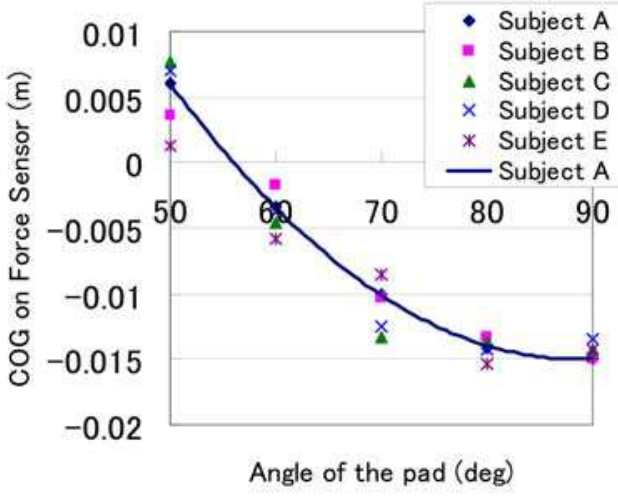

(b) The angular value of the pad

Fig. 8. Relationship between the COG and the applied force.

\section{Seat position adjustment assistance}

\subsection{Required condition}

In general, a failure of sit down has high risk factors for a falling down (Graafmans et al., 1996). Therefore, we questions to nursing specialists on a required assistance for aged people when they move in their home. Their results are the followings.

- Usually, a patient should walk using a walker without force assistance for his rehabilitation.

- However, it is difficult for him to walk backward with exact position enough for seating. Therefore, system should assist this operation part.

- System should assist him with his operation speed for safety reason. Too strong assistance causes his falling from the walker.

For maximizing a rehabilitation performance, the patient walks himself and the system specializes only a seating position adjustment assistance.

\subsection{Assistance algorithm}

For realizing the previous condition, we proposed the following algorithm. The flow chat is as shown in Fig.9. The system is inputted the position and shape data of target chair, bed and toilet etc in the room. 


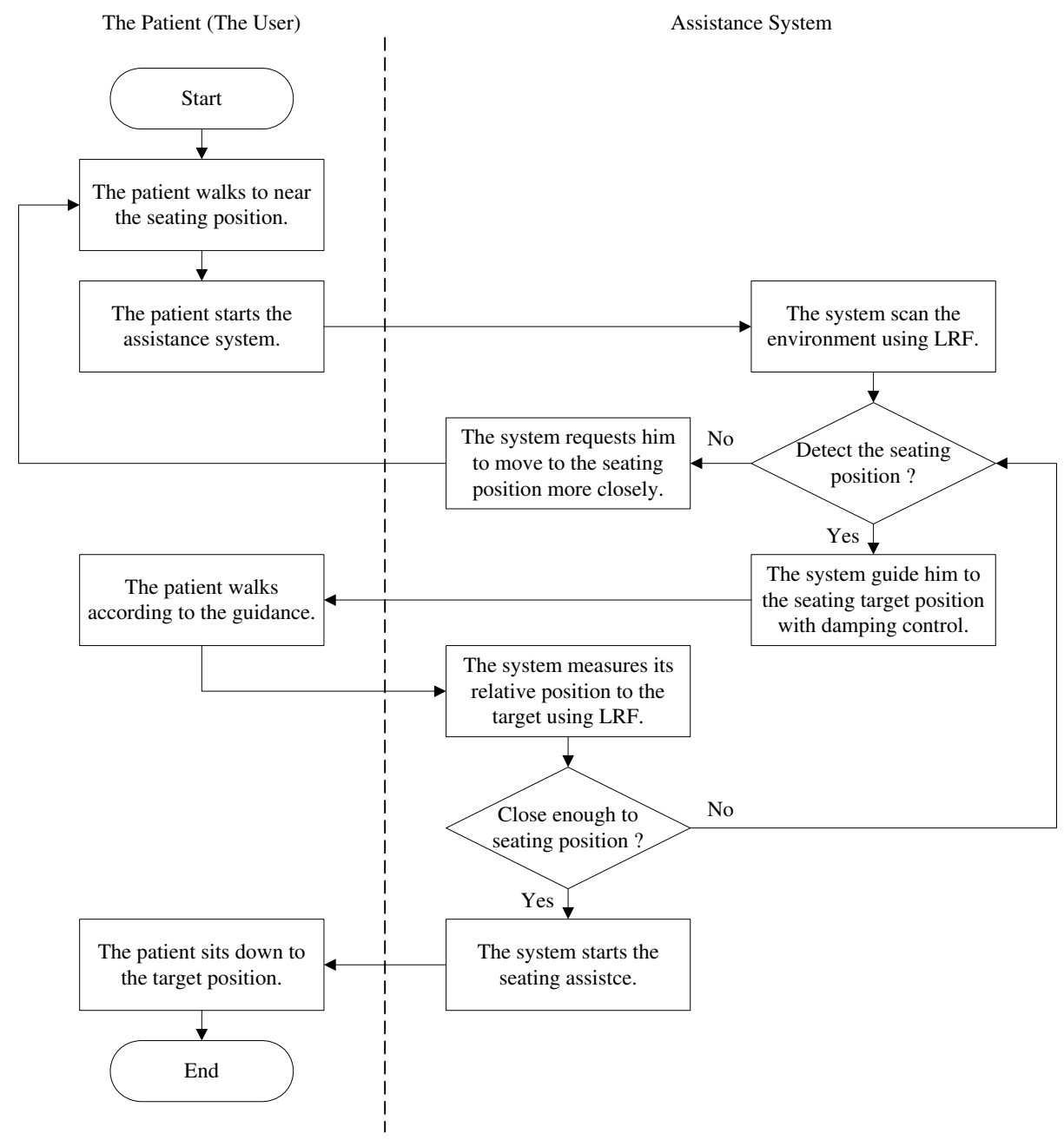

Fig. 9. A flow chart of assistance algorithm.

- System assists only for adjusting the seating position. The user walks by him near the chair, which they want to sit on as Fig.10, and starts the assistance system.

- $\quad$ System receives its position using our developed indoor positioning system (Ohnishi \& Takase, 2003) and detects nearest chair (or bed, toilet) as target.

- System scans around the walker and finds the target using suitable LRF. (In case of Fig.10, LRF1 is suitable. The system detects the target using its shape data (Matsushima et al., 2008).)

- If the system finds the target chair, it assists him to the seating position in front of the target chair.

- If the system cannot find the target chair, it announces the user to go around the target chair. 
We use our indoor positioning system which uses infrared LED (Ohnishi \& Takase, 2003). The system detects infrared LEDs on the walker by the CCD camera with infrared filter on ceiling as Fig.10 and calculates its position using kinematics. The controller of the walker receives its poison data from the server by CORBA network. Using infrared filter, the system is robust and the privacy of the patient is protected because the system only can detect the infrared LEDs. Furthermore, our positioning system can be used in entire room, therefore it will be suitable for room guidance system. (In our future work.)

Our assistance scheme works only at "seating position adjustment", therefore, system requires the patient to move to the target closely. This concept increases rehabilitation performance and realizes the low cost.

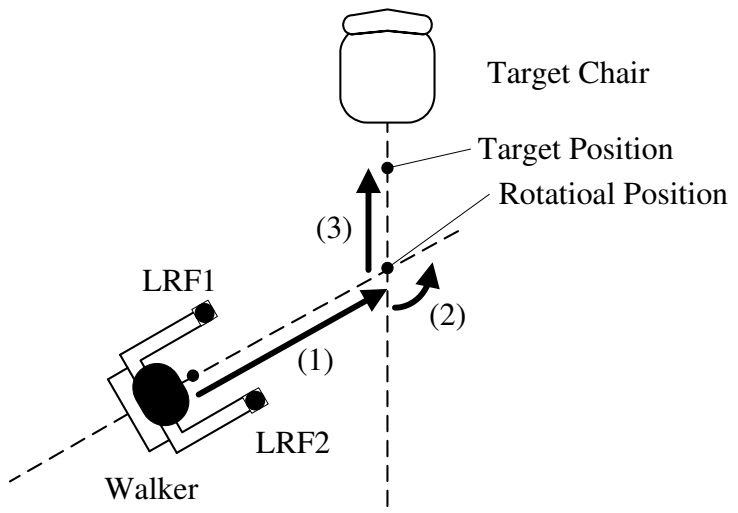

Fig. 10. Path planning to target chair.

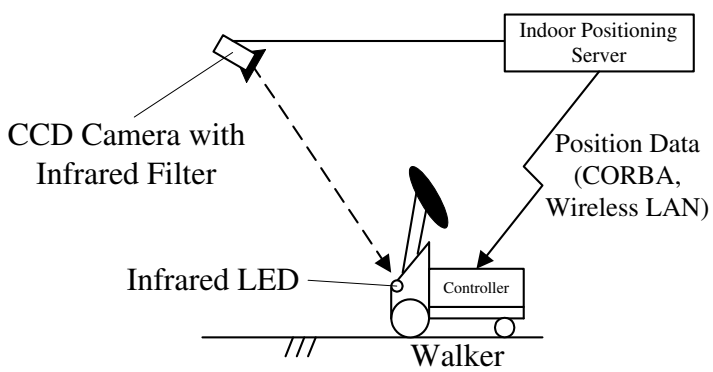

Fig. 11. The indoor positioning system.

\subsection{Guiding to seating position}

From the opinions of nursing specialists, a patient should go straight path especially when he walks to backward. Therefore, after detecting the target chair, our active walker guides a patient using a following path as Fig.10. The first, the walker moves to backward as allow (1) in Fig.10. The second, it rotates at same spot as allow (2) and finally, it moves to the seating position. 
For guiding the patient softly, the system uses a damping control (Chugo et al., 2006) as (7). The coordination is defined in Fig.7.

$$
\tau=c v_{\text {ref }}-B\left(u-u_{0}\right)
$$

where $v_{\text {ref }}$ is velocity control reference which is derived using the position information by LRF between the active walker and the target seating position. $u$ is the applied load to the walker and $u_{0}$ is the threshold which selects from damping control mode and velocity control mode. $c$ and $B$ are coefficients. $\left(B=0\left(\right.\right.$ if $\left.\left.u<u_{0}\right)\right)$

The output force is limited to $\tau_{0}$ as (5) for safety reason.

\section{Experiment}

Here, we verify the performance of our prototype system by the experiment. In this experiment, testers use the special wearing equipment for the experience of the elderly (Takeda et al., 2001). This wear limits the motion of the tester body as elderly.

In this experiment, we test three cases. The first, we test the body stability control during standing up motion. The second, we test the adjustment assistance for the target seating position. Finally, we test the assistance performance for standing up, walking and sitting motion as daily activity.

\subsection{Body stability control}

In this experiment part, the tester stands using our assistance system which utilize our force control scheme (Chugo et al., 2007). The height of the tester is 1.7[m] and our system lifts him at 30[sec]. For verifying an effectiveness of our proposed scheme, we test two cases. One case uses our proposed body stability control scheme and the other case does not use it for standing assistance. The coordination is defined as Fig.8.

Fig.12 shows the standing assistance posture of the subject and Fig.13 shows the movement of our active walker utilizing proposed control during lifting up as Fig.12. After 25[\%] movement pattern, system starts to coordinate the body balance of the patient, because in this period, our assistant manipulator uses force control mode and the posture of the patient is not maintained as references.

Fig.14 shows the COG of the patient and we can verify that our system coordinate the body balance according to the reference of the nursing specialists.

Furthermore, seven aged users test our prototype. They are 67 years old and more, and their care levels of Japanese Long-term Care Insurance System (Population Estimates, 2009) are 1 or 2 .

They stand up using our assistance system twice. One case uses our proposed body stability control scheme and the other case does not use it. We question them about the following topics after standing up with our assistance system.

- Question1: Comparing with standing up using only your own strength, do you feel to easy for standing up using our system? We evaluate the inferior feeling is 1 point, same feeling is 3 points and good feeling is 5 points.

- Question2: Do you feel to fear of falling during standing up using our assistance system? We evaluate the inferior feeling is 1 point, same feeling is 3 points and good feeling is 5 points. 

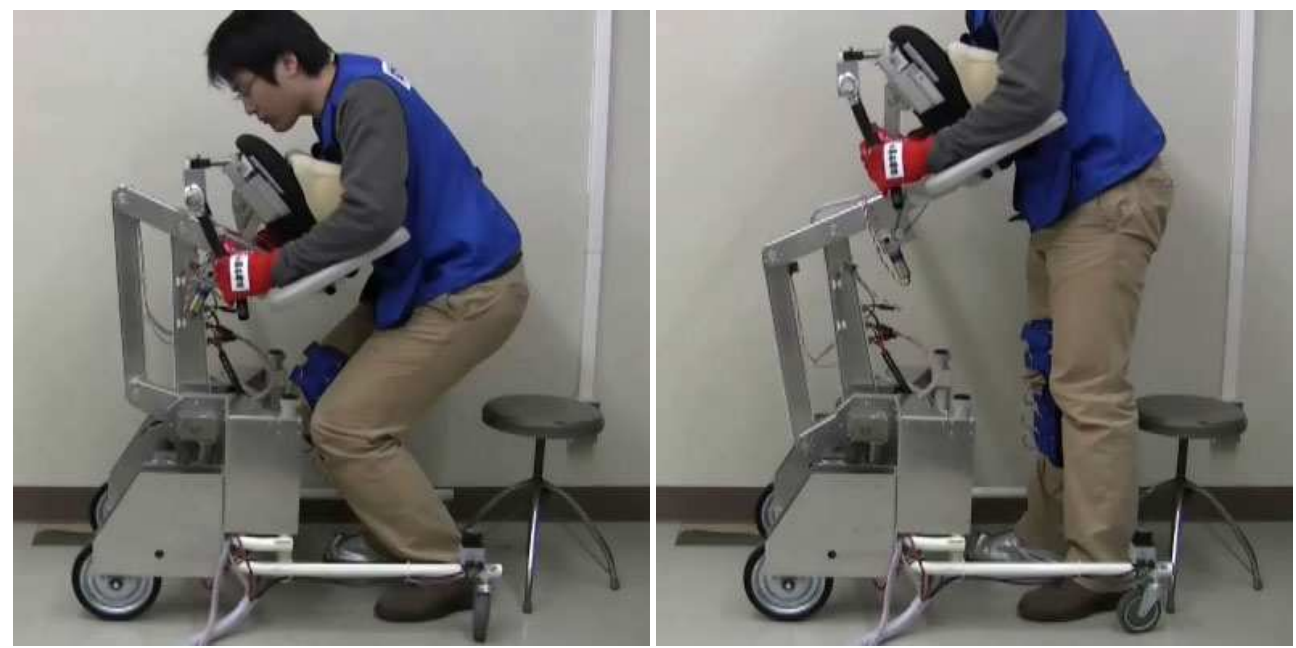

Fig. 12. The posture of the subject during standing assistance.

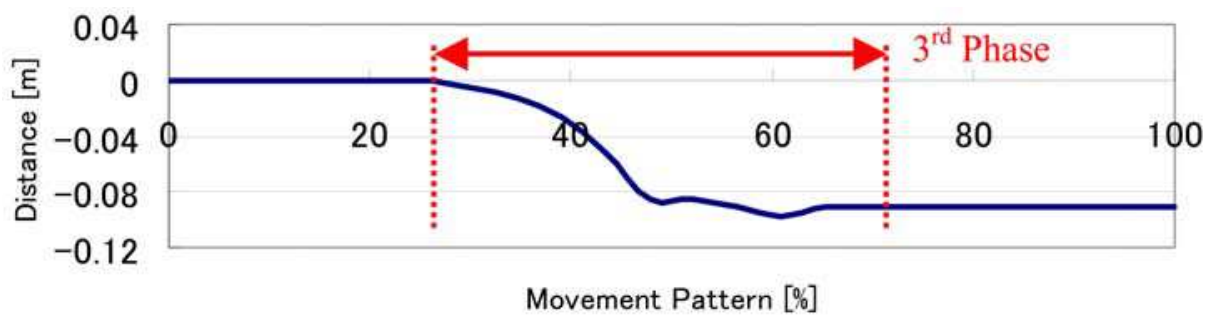

Fig. 13. Movement of the active walker.

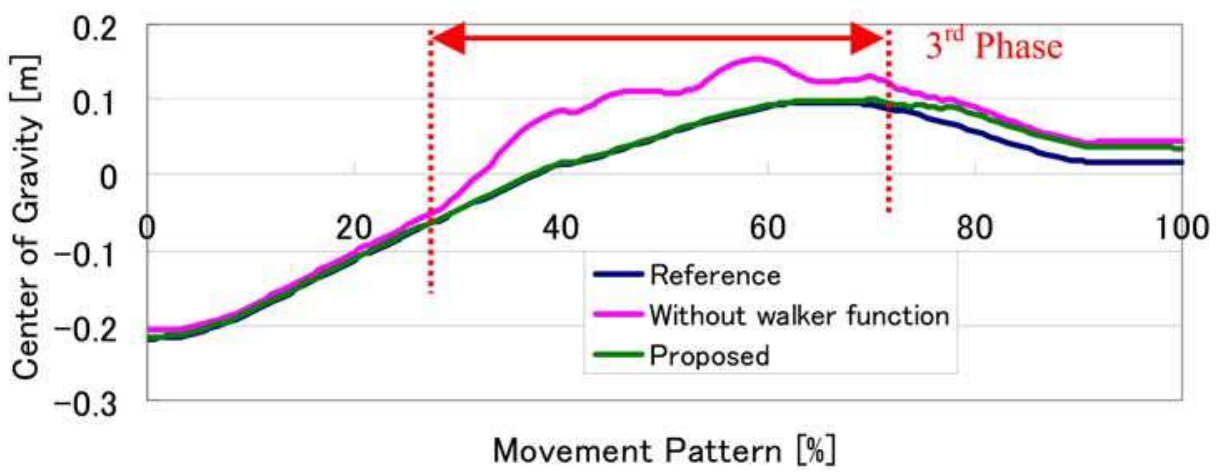

Fig. 14. The position of COG during standing motion. 
Fig.15 shows the opinions of elderly testers. Each bar shows the average and standard deviation of evaluation points in each case. From these results, using our body stability control, the patient feels easier for standing up and does not feel the fear of falling. Therefore, we can evaluate our scheme is effective.

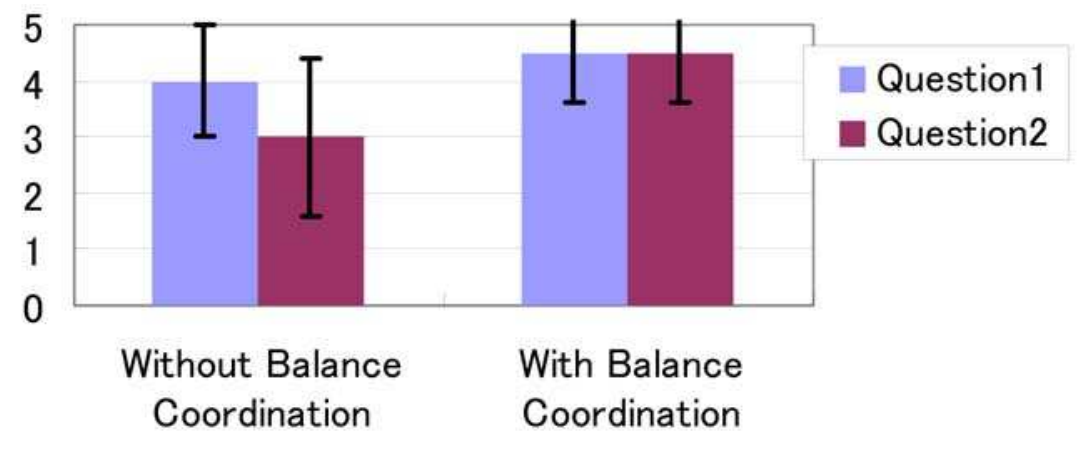

Fig. 15. Organoleptic evaluation of our prototype.

\subsection{Seating position adjustment}

In this experiment part, the tester with wearing equipment (Takeda et al., 2001) walks to the seating position according to our assistance. In preliminary experiment, we set a suitable seating position (and admissible area) which enables the patient to sit down the target chair easily as Fig.16(a). In this experiment, our proposed system guides him to this target position ten times.

From these results as Fig.16(b), our system can adjust the seating position with enough accuracy for sitting down. Our system uses damping control as (8) for safety reason. Thus, the results have a range. (But they are within admissible area.)

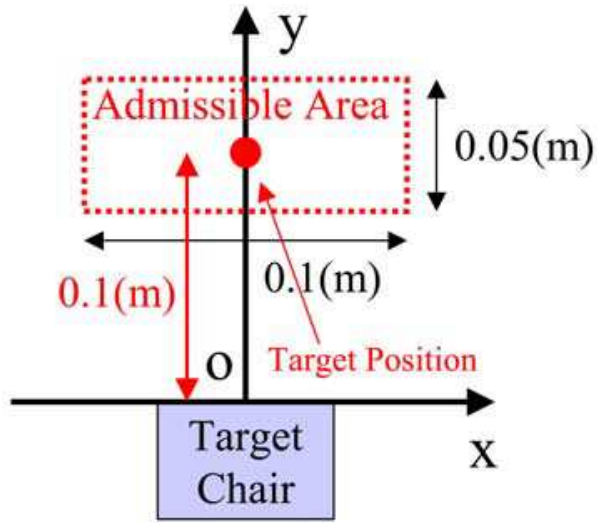

(a) The target seating position

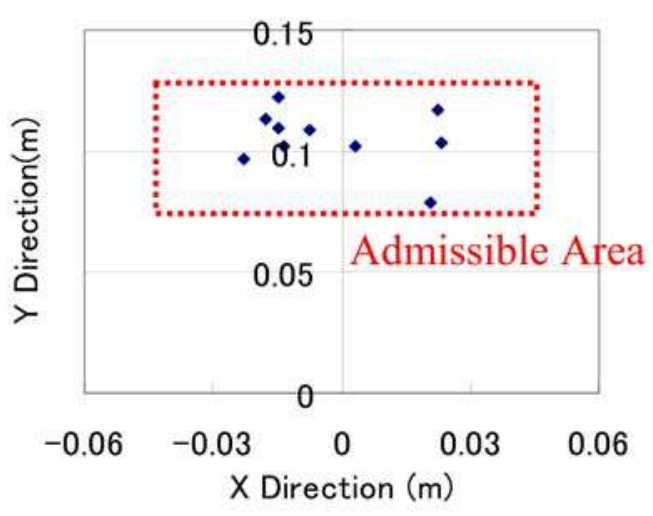

(b) The experimental result

Fig. 16. Assistance to the seating position. 


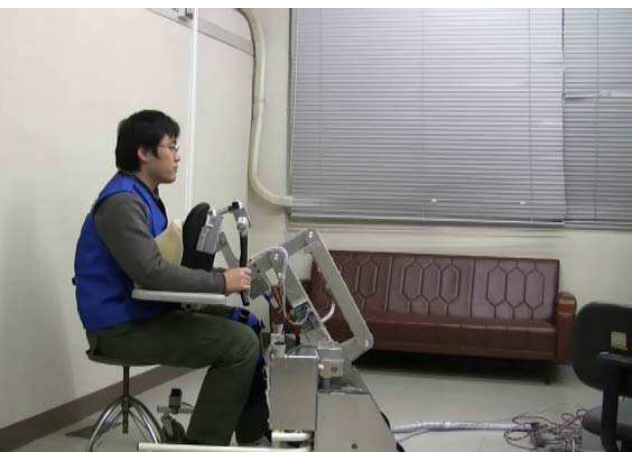

(a)

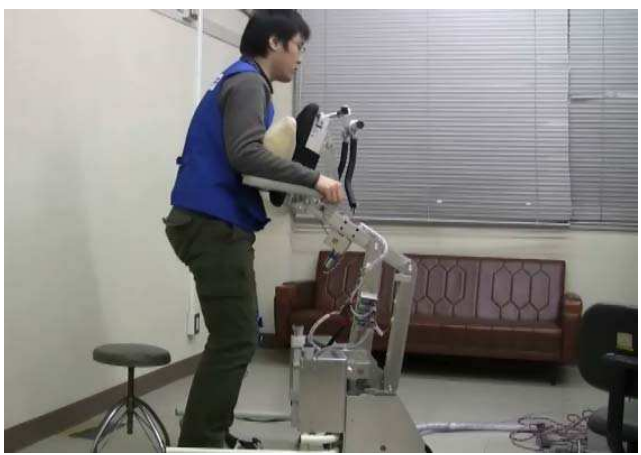

(c)

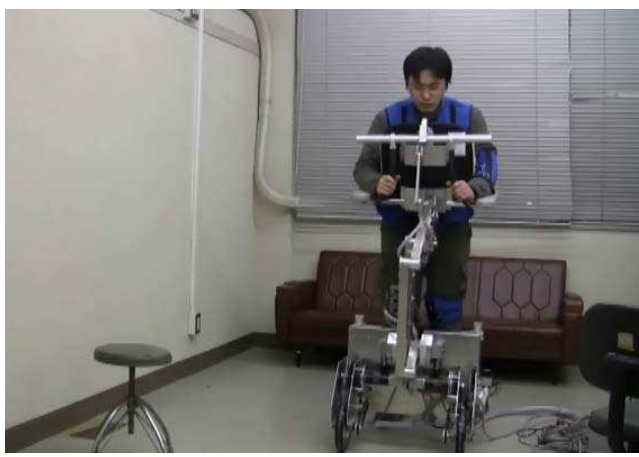

(e)

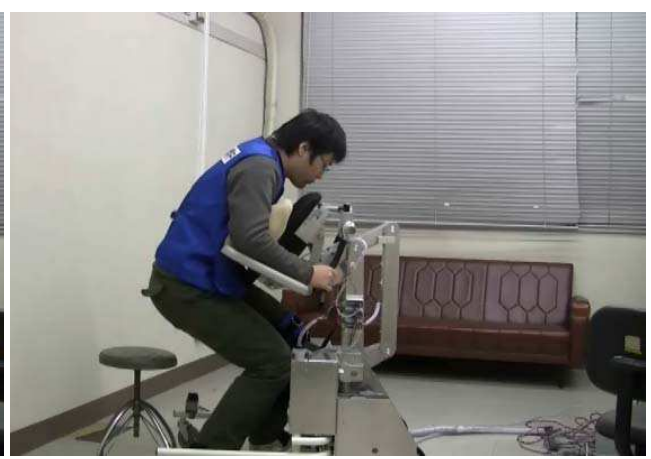

(b)

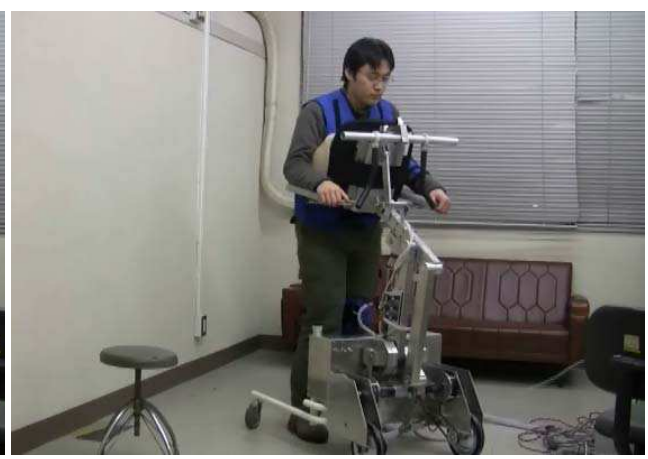

(d)

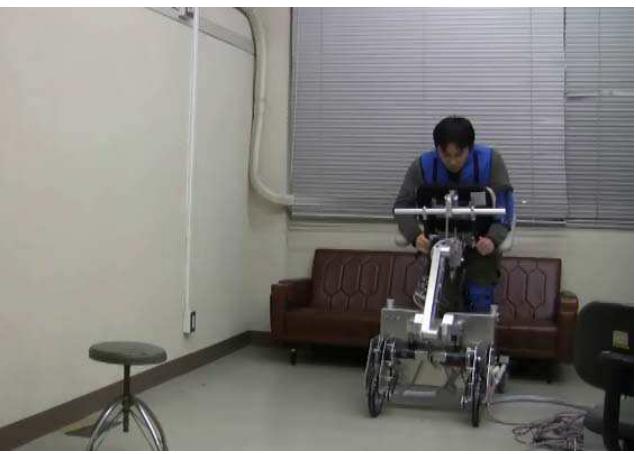

(f)

Fig. 17. Assistance demonstration using our prototype. 


\subsection{General experiment}

Here, we verify the general performance of our prototype system by the experiment. This experiment assumes typical action of elderly (the movement from the chair to the bed in same room) in their daily life.

As the result of the experiment, our system can assist the patient as Fig.17. The first, the tester stands up from the left chair with standing assistance of our proposed system (Fig.17(a)-(c)). The second, he walks to near the target bed himself (Fig.17(c)-(d), Our system does not assist him.). The third, our system adjusts the seating position (Fig.17(d)-(e)) and assists the sit down motion (Fig.17(f)).

\section{Conclusion}

In this paper, we develop an active walker system for standing, walking and seating operation continuously which cooperates the developed standing assistance system with safety and stability. For realizing these conditions, our walker coordinates the assisting position cooperating the standing assistance manipulator according to the posture of the patient. Furthermore, our walker adjusts a seating position when the patient sit down which has high risk for falling down. Using our proposed system, the patient can use standing, walking and seating assistance continuously by a same device.

In our future work, we will discuss the seating assistance operation.

\section{Acknowledgement}

This work was supported in part by the Sasakawa Scientific Research Grant from The Japan Science Society.

\section{References}

Statistics Bureau, Ministry of Internal Affairs and Communications, Japan. (2009). Population Estimates by Age (5-Year Group) and Sex of February 1, 2009, http://www.stat.go.jp/data/jinsui/tsuki/index.htm

Ministry of Health, Labour and Welfare, Japan. (2001). Annual Reports on Health and Welfare 2001 Social Security and National Life, http://www.mhlw.go.jp/toukei/saikin/hw/k-tyosa/k-tyosa01/4-3.html

Alexander, N. B.; Schultz, A. B. \& Warwick, D. N. (1991). Rising From a Chair: Effects of Age and Functional Ability on Performance Biomechanics. J. of Geometry: MEDICAL SCIENCES, Vol.46, No.3, pp.91-98.

Hughes, M. A. \& Schenkman, M. L. (1996). Chair rise strategy in the functionally impaired elderly. J. of Rehabilitation Research and Development, Vol.33, No.4, pp.409412.

Hirvensalo, M.; Rantanen, T. \& Heikkinen, E. (2000). Mobility difficulties and physical activity as predictors of morality and loss of independence in the community-living older population. J. of the American Geriatric Society, Vol.48, pp.493-498. 
Nagai, K.; Nakanishi, I. \& Hanabusa, H. (2003). Assistance of self-transfer of patients using a power-assisting device. Proc. of the IEEE Int. Conf. on Robotics and Automation, Taipei, Taiwan, September 2003, pp.4008-4015.

Funakubo, A.; Tanishiro, H. \& Fukui, Y. (2001). Power Assist System for Transfer Aid. J. of the Society of Instrument and Control Engineers, Vol.40, No.5, pp.391-395.

Chuv, O.; Hirata, Y.; Wang, Z. \& kosuge, K. (2006). Approach in Assisting a Sit-to-Stand Movement Using Robotic Walking Support System. Proc. of the IEEE Int. Conf. on Intelligent Robots and Systems, Beijing, China, October 2006, pp.4343-4348.

Pasqui, V. \& Bidaud, P. (2006). Bio-mimetic trajectory generation for guided arm movement during assisted sit-to-stand transfer. Proc. of the 9th Int. Conf. on Climbing and Walking Robots, Geneva, Belgium, September 2006, pp.246-251.

Chugo, D.; Matsuoka, W.; Sogmin, J. \& Takase, K. (2006). Rehabilitation Walker with Standing-Assistance Device. J. of Robotics and Mechatronics, Vol.19, No.6, pp. 604-611.

Hatayama, T. \& Kumagai, S. (2004). Falls, physical disability, and mental distress in the elderly, J. of Health Science, Vol.26, pp.21-30.

Chugo, D. \& Takase, K. (2008). Walker System with Assistance Device for Standing-Up. Proc. of JSME Conf. on Bio Mechanics, AIST, Tsukuba, Japan, September 2008, pp.4447.

Maki, E.; Holliday, P. J. \& Topper, A. K. (1991). Fear of falling and postural performance in the elderly, J. of Gerontology, No.46, Vol.4, pp.123-131.

Kamiya, K. (2005). Development and evaluation of life support technology in nursing. Proc. of Proc. of 7th RACE Symp., Research into Intelligent Artifacts for the Generalization of Engineering, The Univ. of Tokyo, Tokyo, Japan, January 2005, pp.116-121.

Chugo, D.; Okada, E.; Kawabata, K.; Kaetsu, H.; Asama, H.; Miyake, N. \& Kosuge, K. (2006). Force Assistance Control for Standing-Up Motion. Proc. of the IEEE/RASEMBS Int. Conf. on Biomedical Robotics and Biomechatoronics, Pisa, Italy, February 2006, F132.

Nuzik, S.; Lamb, R.; Vansant, A. \& Hirt, S. (1986). Sit-to-Stand Movement Pattern, A kinematic Study. Physical Therapy, Vol.66, No.11, pp.1708-1713.

Schenkman, M.; Berger, R. A.; Riley, P. O.; Mann, R. W. \& Hodge, W. A. (1990). Whole-Body Movements During Rising to Standing from Sitting. Physical Therapy, Vol.70, No.10, pp.638-648.

Takeda, K.; Kanemitsu, Y. \& Futoyu, Y. (2001). Understanding the Problem of the Elderly through a Simulation Experience - Difference in the Effect between Before and After Clinical Practice -. Kawasaki Medical Welfare J., Vol.11, No.1, pp. 64-73.

Graafmans, W. C.; Ooms, M. E.; Hofstee, H. M. A.; Bezemer, P. D.; Bouter, L. M. \& Lips, P. (1996). Falls in the Elderly: A Prospective Study of Risk Factors and Risk Profiles. American J. of Epidemiology, Vol.143, No.11, 1129-1136.

Ohnishi, T. \& Takase, K. (2003). Study on a Holonomic Omnidirectional Power Wheelchair Integration of Manual and Automatic Control-. IEEJ Trans. on Electronics, Information and Systems, Vol.123, No.6 pp.1109-1116. 
Matsushima, S.; Chugo, D. \& Takase, K. (2008). AGV Navigation using iGPS, Proc. of 8th Annual Conf. on System Integration, SICE, Gifu, Japan, December 2008, pp.365-366. 


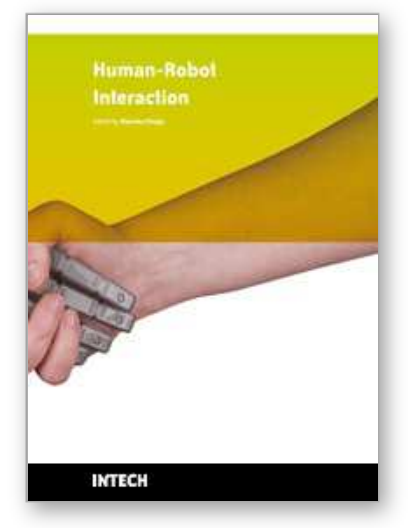

\author{
Human-Robot Interaction \\ Edited by Daisuke Chugo
}

ISBN 978-953-307-051-3

Hard cover, 288 pages

Publisher InTech

Published online 01, February, 2010

Published in print edition February, 2010

Human-robot interaction ( $\mathrm{HRI}$ ) is the study of interactions between people (users) and robots. $\mathrm{HRI}$ is multidisciplinary with contributions from the fields of human-computer interaction, artificial intelligence, robotics, speech recognition, and social sciences (psychology, cognitive science, anthropology, and human factors). There has been a great deal of work done in the area of human-robot interaction to understand how a human interacts with a computer. However, there has been very little work done in understanding how people interact with robots. For robots becoming our friends, these studies will be required more and more.

\title{
How to reference
}

In order to correctly reference this scholarly work, feel free to copy and paste the following:

Daisuke Chugo and Kunikatsu Takase (2010). A Motion Control of a Robotic Walker for Continuous Assistance during Standing, Walking and Seating Operation, Human-Robot Interaction, Daisuke Chugo (Ed.), ISBN: 978953-307-051-3, InTech, Available from: http:/www.intechopen.com/books/human-robot-interaction/a-motioncontrol-of-a-robotic-walker-for-continuous-assistance-during-standing-walking-and-seating-o

\section{INTECH}

open science / open minds

\section{InTech Europe}

University Campus STeP Ri

Slavka Krautzeka 83/A

51000 Rijeka, Croatia

Phone: +385 (51) 770447

Fax: +385 (51) 686166

www.intechopen.com

\section{InTech China}

Unit 405, Office Block, Hotel Equatorial Shanghai

No.65, Yan An Road (West), Shanghai, 200040, China

中国上海市延安西路65号上海国际贵都大饭店办公楼405单元

Phone: $+86-21-62489820$

Fax: +86-21-62489821 
(C) 2010 The Author(s). Licensee IntechOpen. This chapter is distributed under the terms of the Creative Commons Attribution-NonCommercialShareAlike-3.0 License, which permits use, distribution and reproduction for non-commercial purposes, provided the original is properly cited and derivative works building on this content are distributed under the same license. 